\title{
DISKUSSION
}

\section{Bundesrat und Europapolitik - kein kontrollfreier Raum. Eine Replik auf Erich Röper in Heft 1/2009 der ZParl ${ }^{1}$}

\author{
Reinhard Hönle
}

In seinem Aufsatz kritisiert Erich Röper die fehlende parlamentarische Kontrolle europapolitischer Beschlüsse des Bundesrates. Die pauschale Aussage, „kein Landtag hat sich mit den Stellungnahmen des Bundesrats nach Art. 23 Abs. 5 GG befasst, sie gar kontrolliert, seien sie maßgeblich oder nicht - falls er sie überhaupt zu Gesicht bekam “2 , fordert Widerspruch heraus. Die Behauptung, die europapolitischen Beschlüsse der Landesregierungen im Bundesrat würden durch die Landesparlamente nur unzureichend kontrolliert, wird zumindest der Praxis des Landtags von Baden-Württemberg nicht gerecht.

Die Aussage des Autors ist umso fragwürdiger, als sich der Landtag von Baden-Württemberg im Rahmen seiner landesinternen Mitwirkung an Angelegenheiten der Europäischen Union nach Artikel 34a Landesverfassung allein in der aktuellen Wahlperiode (seit Juni 2006) mit rund 40 EU-Vorhaben befasst hat. ${ }^{3}$ Hervorzuheben ist in diesem Zusammenhang, dass sich der Landtag bei der Behandlung von EU-Vorlagen nicht darauf beschränkt, nachträglich die europapolitische Beschlussfassung der Landesregierung im Bundesrat zu kontrollieren. Vielmehr nimmt das Parlament zu landesrelevanten Vorhaben, die die Gesetzgebungsbefugnis der Länder betreffen oder sonst von herausragender politischer Bedeutung für das Land sind, bereits Stellung, bevor sie im Bundesrat behandelt werden. Auf diese Weise wird gesichert, dass die Landesregierung bei ihrer Positionierung im Bundesrat die Stellungnahmen des Landtags in ihre Willensbildung einbeziehen kann.

Im Interesse einer frühzeitigen Einflussnahme befasst sich das Parlament zudem nicht nur mit endgültigen Richtlinien- und Verordnungsentwürfen der Europäischen Kommission, sondern äußert sich bereits in der prälegislativen Phase etwa zu Grün- und Weißbüchern.

$\mathrm{Zu}$ zahlreichen EU-Angelegenheiten hat der Landtag auch inhaltliche Beschlüsse gefasst, zum Beispiel zum Grünbuch „Hin zu einer neuen Mobilität für die Stadt “4 oder zum Entwurf der Bodenschutzrichtlinie 5 . In diesen Fällen forderte der Landtag die Landesregierung auf, die EU-Vorhaben aufgrund von Verstößen gegen das Subsidiaritätsprinzip im Bundes-

1 Erich Röper, Europapolitische Bundesratsbeschlüsse ohne demokratisch-parlamentarische Kontrolle, in: ZParl, 40. Jg. (2009), H. 1, S. 3 - 15.

2 Ebenda, S. 11.

3 Die Liste der EU-Vorhaben ist zu finden in der Parlamentsdokumentation des Landtags (http:// www.landtag-bw.de/dokumente/parlamentsdokumentation/index.asp) unter dem Schlagwort „Europa, Unterrichtung des Ltg in EU-Angelegenheiten“.

4 Vgl. Mitteilung des Innenministeriums von Baden-Württemberg vom 12. November 2007, LT-Drs. 14/1982.

5 Vgl. Mitteilung des Umweltministeriums von Baden-Württemberg vom 13. Oktober 2006, LT-Drs. 14/438. 
rat abzulehnen ${ }^{6}$, und die Landesregierung folgte den Beschlüssen. ${ }^{7}$ Diese Beispiele zeigen, dass die Landtage - auch wenn sie ihre Regierungen im Bundesrat rechtlich nicht binden können ${ }^{8}$ - in der Praxis erfolgreich auf deren Europapolitik im Bundesrat einwirken können.

$\mathrm{Zu}$ widersprechen ist ferner der Aussage des Autors, dass es zu den Feinstaubrichtlinien keine öffentliche Diskussion in den Landtagen gegeben habe. ${ }^{9}$ In Baden-Württemberg ist im Jahr 1998 im Rahmen der Unterrichtung nach Artikel 34a Landesverfassung sehr wohl über den Richtlinienentwurf über Grenzwerte für Schwefeldioxid, Stickstoffoxide, Partikel und Blei in der Luft (so genannte Feinstaubrichtlinie) ${ }^{10}$ informiert worden, und das Parlament hat diesen Entwurf nach der Diskussion im zuständigen Ausschuss auch in öffentlicher Plenarsitzung behandelt. ${ }^{11}$

Schließlich ist der Landtag von Baden-Württemberg auch im Hinblick auf die Subsidiaritätskontrolle nicht untätig geblieben. Bereits im Jahr 2007 wurde mit der Landesregierung eine Vereinbarung getroffen, wonach diese zu jedem dem Parlament zugeleiteten EUVorhaben eine erste Einschätzung liefert, ob es sich im Rahmen der EU-Kompetenz bewegt und das Subsidiaritäts- sowie Verhältnismäßigkeitsprinzip eingehalten sind. ${ }^{12}$ Gerade der Europaausschuss des Landtags, der zu Beginn der 14. Wahlperiode 2006 eingesetzt wurde, was Röper in seinem Beitrag nicht registriert ${ }^{13}$, sieht es als seine zentrale Aufgabe an, auf die Einhaltung des Subsidiaritätsprinzips zu achten.

Die europapolitische Praxis des Landtags von Baden-Württemberg belegt, dass die Landesparlamente bereit und in der Lage sind, europapolitische Beschlüsse der Landesregierungen im Bundesrat kritisch zu begleiten. Nicht zuletzt trägt die öffentliche Behandlung landesrelevanter EU-Vorhaben in den Landtagen aufgrund ihrer Öffentlichkeits- und Mittlerfunktion dazu bei, dass sich zu europäischen Fragen eine Diskussionskultur herausbildet, wie sie für die nationale Politik selbstverständlich ist. ${ }^{14}$ Hier bleibt noch ein gutes Stück Weg zu gehen, wie die geringe Beteiligung an der Wahl zum Europäischen Parlament gezeigt hat.

6 Zum Grünbuch vgl. Beschluss des Landtags von Baden-Württemberg, Plenarprotokoll 14/38 vom 19. Dezember 2007, S. 2551; zur Bodenschutzrichtlinie vgl. Beschluss des Landtags von Baden-Württemberg, Plenarprotokoll 14/12 vom 9. Dezember 2006, S. 640.

7 Vgl. Stellungnahme des Staatsministeriums von Baden-Württemberg zum Antrag der Fraktion der Grünen „Europakompetenz des Landes - Subsidiaritätsprüfung - Mitgestaltung statt Abwehr" vom 8. April 2009, LT-Drs. 14/4341, S. 16, S. 18.

8 Vgl. BVerfGE 8, S. 104 ff., S. 120 f.

9 Vgl. Erich Röper, a.a.O. (Fn. 1), S. 9 f.

10 Vgl. Mitteilung des Umweltministeriums von Baden-Württemberg vom 13. Januar 1998, LT-Drs. 12/2364.

11 Vgl. Beschlussempfehlung und Bericht des Umwelt- und Verkehrsausschusses vom 5. März 1998, LT-Drs. 12/2579; Plenarprotokoll 12/43 vom 11. März 1998, S. 3426 f.

12 Abgedruckt in: Siegfried Frech / Martin Große Hüttmann / Reinhold Weber (Hrsg.), Handbuch Europapolitik, Stuttgart 2009, S. 335 f.

13 Vgl. Erich Röper, a.a.O. (Fn. 1), S. 11.

14 Vgl. Peter Straub, Das Frühwarnsystem zur Subsidiaritätskontrolle im Vertrag von Lissabon als Hürde vor weiterer Zentralisierung in der Europäischen Union?, in: Europäisches Zentrum für Föderalismus-Forschung Tübingen (Hrsg.), Jahrbuch des Föderalismus 2008, Baden-Baden 2008, S. $15-27$, S. 27. 